ISSN 2087-3336 (Print) | 2721-4729 (Online)

TEKNOSAINS: Jurnal Sains, Teknologi dan Informatika

Volume 8, Nomor 1, Januari 2021, hlm. 23-31

http://jurnal.sttmcileungsi.ac.id/index.php/tekno

DOI: 10.37373

\title{
ANALISIS KEGAGALAN REM HINO FG 235 DENGAN MENGGUNAKAN METODE FISHBONE ANALISIS
}

\section{FAILURE ANALYSIS OF HINO FG 235 BRAKES By THE PROCESS OF FISHBONE ANALYSIS}

\author{
Sugiharjo, Wilarso* \\ Program Studi Teknik Mesin, Sekolah Tinggi Teknologi Muhammadiyah Cileungsi, Cileungsi, Bogor, Jawa \\ Barat, Indonesia 16820 \\ *Koresponden email: wilarso@sttmcileungsi.ac.id
}

\begin{abstract}
ABSTRAK
Berawal dari tekanan angin yang cepat habis atau rendah, ketika dilakukan pengereman berkali-kali pada saat jalan padat merayap. Tujuan dari penelitian untuk mengetahui kegagalan proses pengereman, agar tidak terulang kembali. Adapun metode dalam penelitian ini menggunakan fishbone analysis. Dari hasil penelitian kecelakaan truk yang sering terjadi kegagalan pengereman yang disebabkan oleh tekanan angin rendah, adanya gelembung udara pada minyak rem, muatan berlebih, dan disebabkan kurang pengetahuan pengemudi saat mengendarai mobil truk. Pada kegagalan rem mobil truk HINO FG 235, disebabkan oleh tekanan angin kurang, sehingga mengalami kegagalan proses pengereman. Solusi dalam penelitian ini sebelum mengemudikan truk harus melakukan pengecekan tekanan angin di tangki penampungan, membuang kondensasi pada tangki udara, serta menguji sistem pengereman sebelum dioperasikan.
\end{abstract}

Kata Kunci : Truk, Rem, Perawatan, HINO FG 235.

\section{ABSTRACT}

Starting from wind pressure that quickly runs out or is low, when braking repeatedly when the road is congested. The purpose of this research is to determine the failure of the braking process, so that it does not happen again. The method in this study uses fishbone analysis. From the results of truck accident research, braking failure often occurs due to low wind pressure, air bubbles in the brake fluid, overloading, and due to the driver's lack of knowledge when driving a truck. The brake failure of the HINO FG 235 truck car was caused by insufficient wind pressure, so the braking process failed. The solution in this study before driving the truck is to check the wind pressure in the storage tank, remove condensation on the air tank, and test the braking system before it is operated.

Keywords: Truck, Brakes, Maintenance, HINO FG 235.

\section{PENDAHULUAN}

TEKNOSAINS: Jurnal Sains, Teknologi \& Informatika is licensed under a Creative Commons Attribution-NonCommercial 4.0 International License. ISSN 2087-3336 (Print) | 2721-4729 (Online) 
Masalah pada rem kendaraan tipe air over hydraulic, berawal dari tekanan angin yang cepat habis atau tekanan cepat berkurang ketika dilakukan pengereman berkali-kali pada saat jalan padat merayap atau macet. Sedangkan beberapa kasus pada kendaraan yang sudah menempuh jarak kurang lebih $60.000 \mathrm{~km}[1]$.

Pada kendaraan Hino FG produksi sebelum tahun 2015 masih menggunakan rem tipe air over hydraulic[2], pada tipe rem ini sangat bergantung pada tekanan angin di sistem, apabila tekanan normal, maka rem akan berfungsi normal dan apabila tekanan angin berkurang maka proses pengereman menjadi tidak maksimal/kurang pakem dan bisa mengakibatkan blong serta membahayakan pengemudi dan orang lain[3][4].

Seperti sudah dipahami, rem kendaraan berfungsi untuk menghentikan laju kecepatan[5]. Hal ini sangat penting karena terkait dengan keselamatan pengemudi, penumpang, maupun orang lain di jalan raya. Rem akan berfungsi dengan maksimal apabila dilakukan perawatan dan penyetelan secara berkala, karena komponen-komponen rem bisa aus karena penggunaan. Pada tipe rem ini penyetelannya tidak otomatis, tetapi dilakukan secara manual [6][5].

Akibat keausan pada kampas rem, tekanan angin juga bisa terganggu apabila ada pemasangan komponen angin tambahan yang tidak standar, seperti ada tambahan klakson angin, hal ini akan mempengaruhi kinerja sistem rem terkait penggunaan [7].

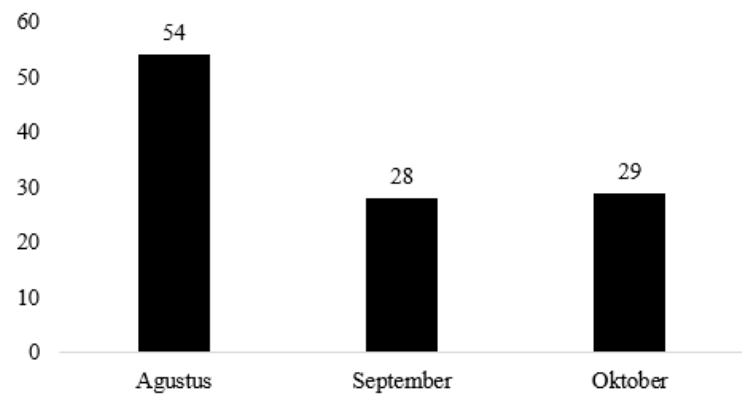

Gambar 1. Jumlah kerusakan unit.

Pada gambar 1 dijelaskan bahwa selama bulan Agustus-Oktober terjadi kerusakan pada unit truk Hino FG 235 yang ada keterkaitan dengan proses pengereman. Trend kerusakan tersebut perlu perhatian pada bagian manajemen PT. X, supaya bisa meningkatkan kinerja unit truk.

Gambar 2 menunjukkan cara kerja rem tipe Air Over Hydraulic. Perintah rem dari pedal rem menggunakan angin dan mendorong valve (relay valve) di air master sehingga angin dari tangki angin dengan tekanan dan aliran udara yang lebih besar mendorong piston di air master dengan diameter yang lebih besar mendorong piston hidrolik dan menekan minyak rem melalui pipa-pipa saluran ke cylinder brake di roda dan mendorong kampas rem sehingga menekan tromol untuk menghentikan putaran roda (2)[8].

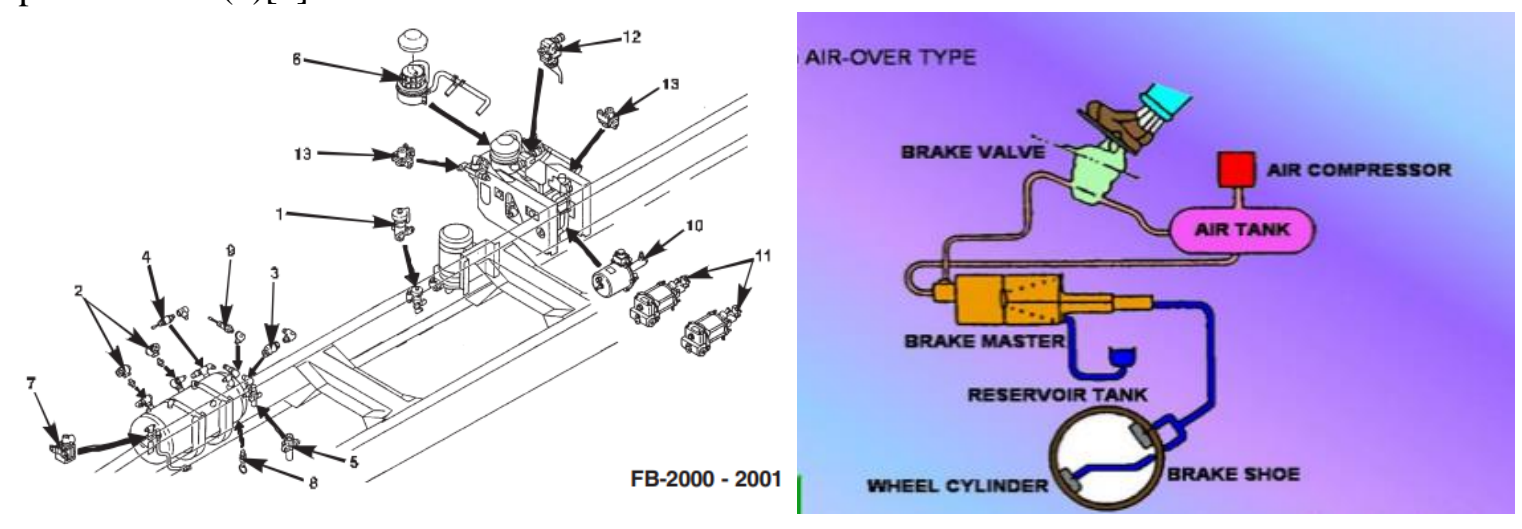

Gambar 2. Air over hydraulic brake system [9]. 
Tujuan dari penelitian ini adalah untuk menentukan akar penyebab kegagalan proses pengereman pada kendaraan truk Hino FG 235 di salah satu unit PT. X [1][10]. Teknik analisis yang dipergunakan adalah metode fishbone analysis. Dari penelitian ini diharapkan agar kejadian tersebut tidak terjadi lagi pada unit lain dan bisa menjadi acuan penelitian yang menggunakan kendaraan dengan rem type air over hydraulic [11].

\section{METODE}

Penelitian ini dilakukan dengan metode deskriptif untuk menggambarkan secara sistematis, serta akurat sesuai dengan fakta-fakta yang dilakukan penelitian dalam hal ini perawatan pada rem truk agar bisa bekerja dengan optimal, sehingga bisa diketahui langkah perbaikan.

Penelitian ini dimulai dari identifikasi masalah pada kerusakan unit yang ada kaitannya dengan pengereman. Kemudian pengumpulan data terhadap jenis equipment yang sering rusak. Analisis data menggunakan metode fishbone analysis dan kesimpulan dalam analisis untuk menentukan rekomendasi perbaikan.

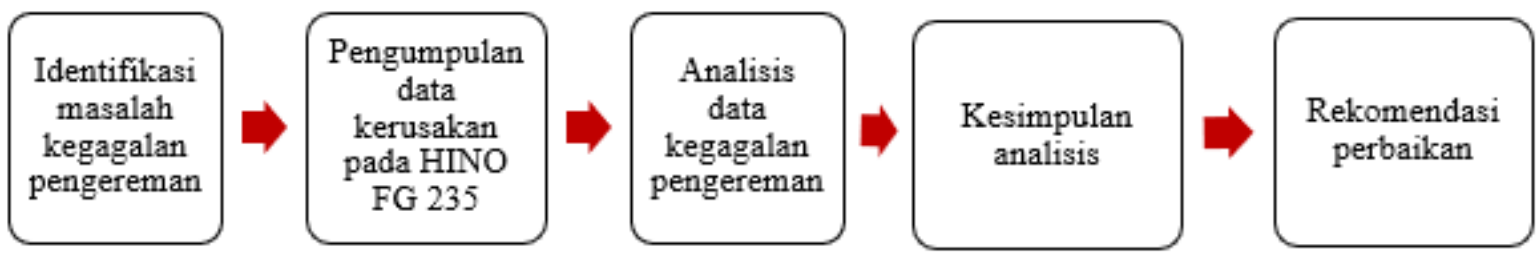

Gambar 3. Alir penelitian.

\section{HASIL DAN PEMBAHASAN}

Ketika pengemudi mengoperasikan truk Hino FG 235 pada jalan turunan dan macet, beberapa kali menginjak pedal rem angin terus turun dan sensor tekanan menyala, pengemudi berusaha mengerem, namun tidak berfungsi dengan baik, akhirnya pengemudi menarik rem tangan agar kendaraan berhenti[12]. Pengemudi kemudian menambahkan tekanan angin sampai penuh pada tabung angin, untuk kembali ke bengkel. Dalam pengecekan yang di workshop meliputi fungsi dari sensor tekanan angin, fungsi sensor stroke dari air master, fungsi sensor level minyak rem, kondisi kampas rem, pipa pipa rem, air master, silinder rem dan melakukan pengetesan, sesuai dengan gambar 4 .

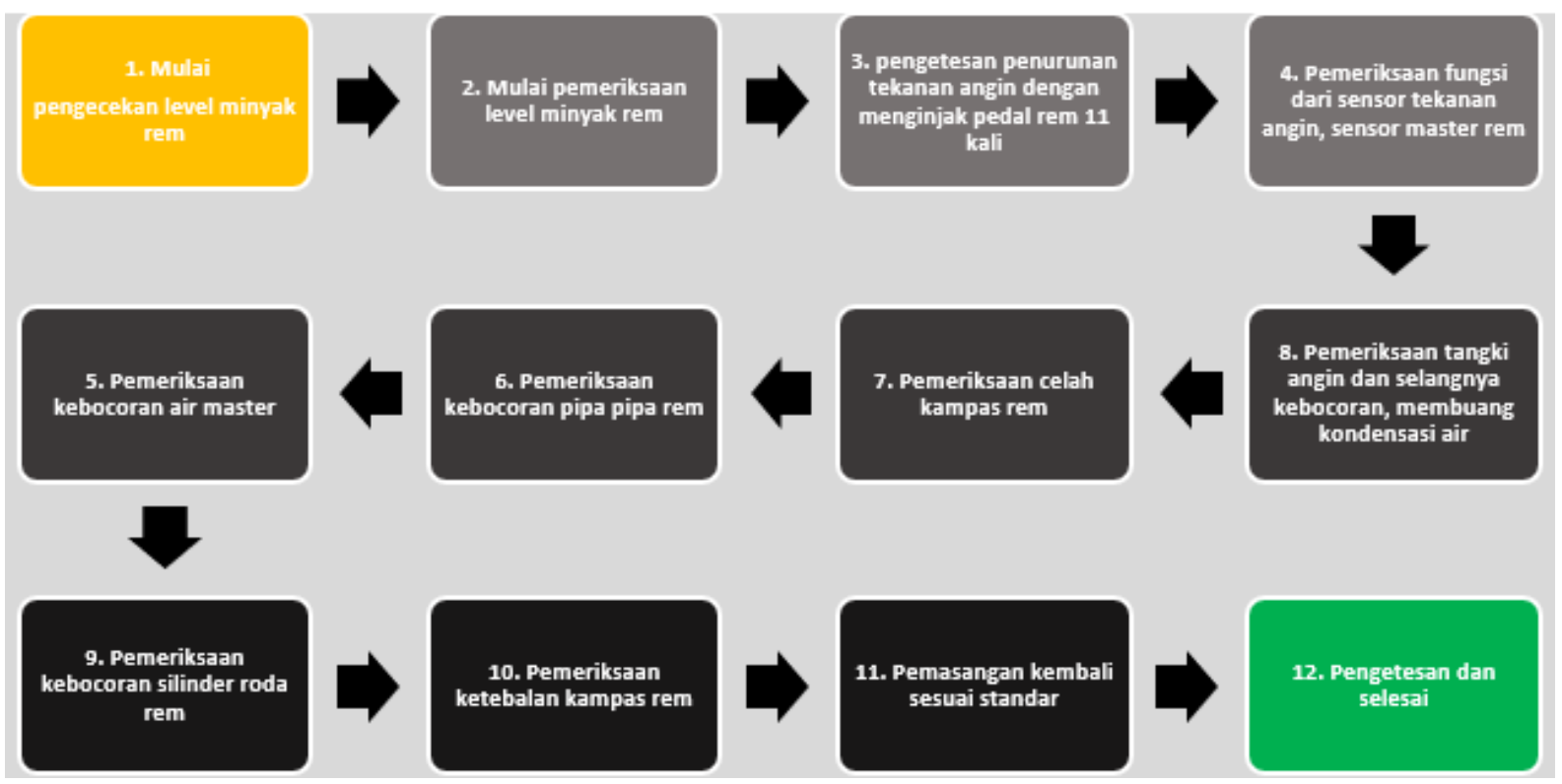

Gambar 4. Flow pengecekan rem air over hydraulic.

\subsection{Pemeriksaan.}



FISHBONE ANALISIS

Sensor level minyak rem berfungsi untuk menginformasikan kalau level minyak rem kurang dari standarnya. Ini terjadi karena bocor atau penguapan. Jika lampu indikator akan menyala di dashboard, maka ada kerusakan pada sensor level dan yang harus dilakukan adalah perbaikan atau mengganti sensor baru, sesuai gambar 5 .

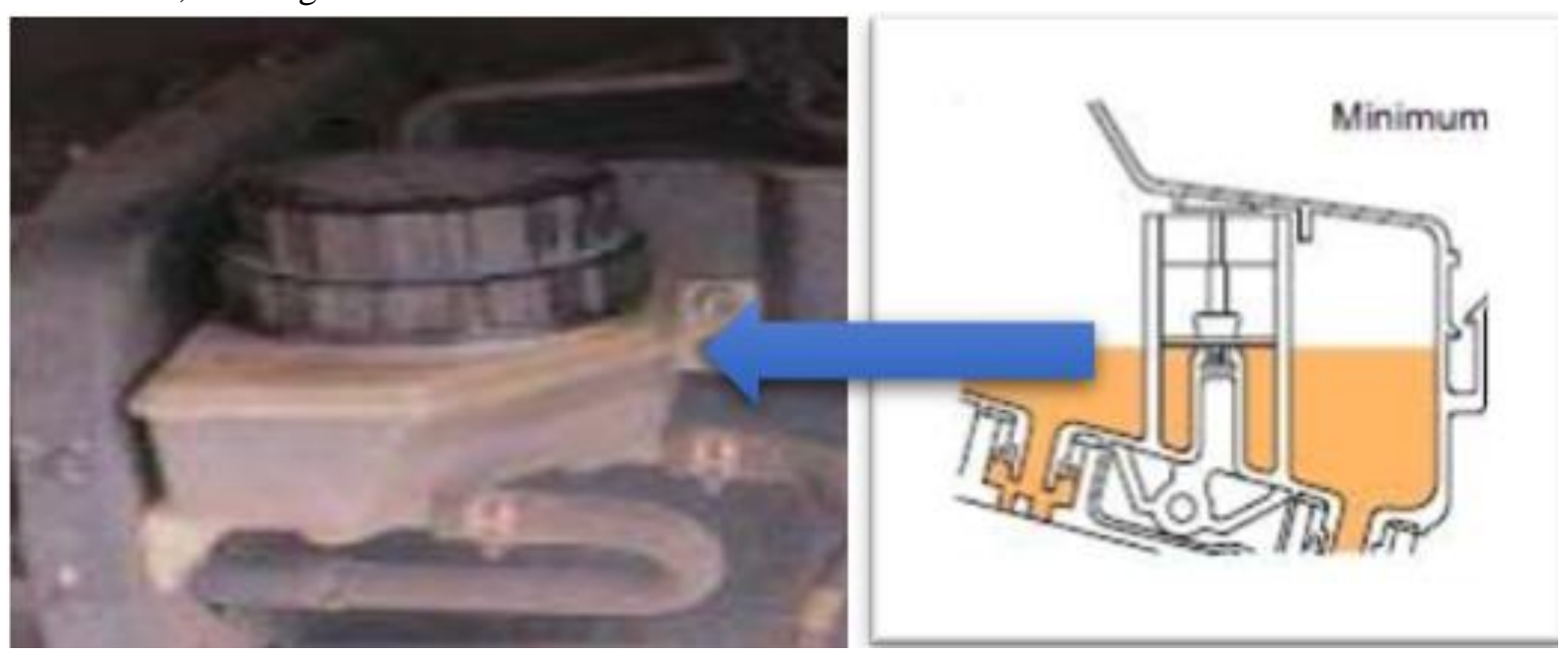

Gambar 5. Sensor level brake fluid.

Pemeriksaan sensor air pressure dan suplai angin, untuk menginformasikan apabila tekanan angin di tangki kurang dari 5 bar, maka lampu indikator di dashboard menyala dan alarm berbunyi, truk harus berhenti untuk mengisi angin, dan memeriksa kebocoran dan harus dilakukan pemeriksaan kompresor angin. Dari hasil pemeriksaan pengisian angin masih normal sampai 9 bar. Pada saat kondisi truk diam dan putaran mesin langsam dilakukan pengereman sampai 12 kali sensor tekanan baru menyala, dan kondisi normal, sesuai dengan gambar 6[13].

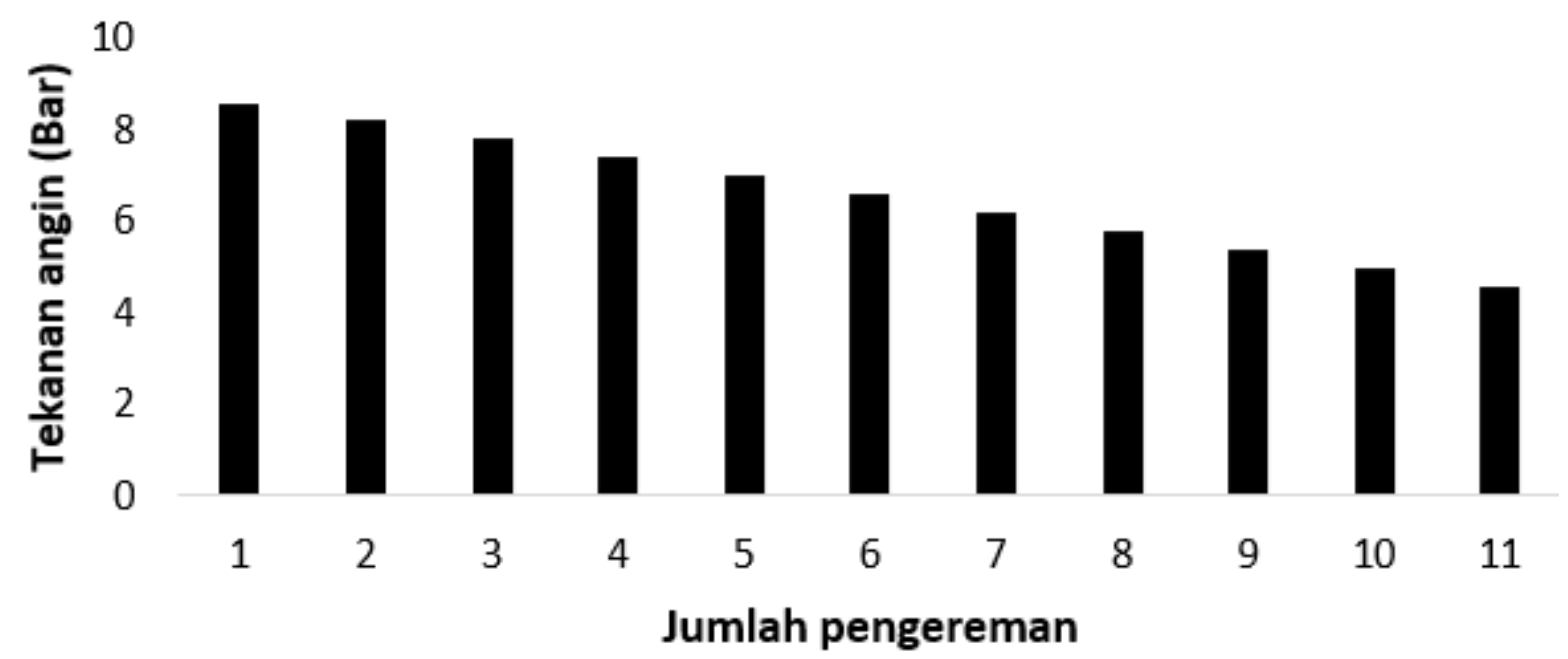

Gambar 6. Test tekanan angin sebelum celah kampas rem di setel.

Apabila jarak main piston air master terlalu panjang. Apabila celah kampas rem sudah terlalu lebar atau terjadi masalah pada piston hidrolik seal-nya sudah lemah, atau kebocoran pada pipa remnya, maka sensor air master piston stroke akan berfungsi. 


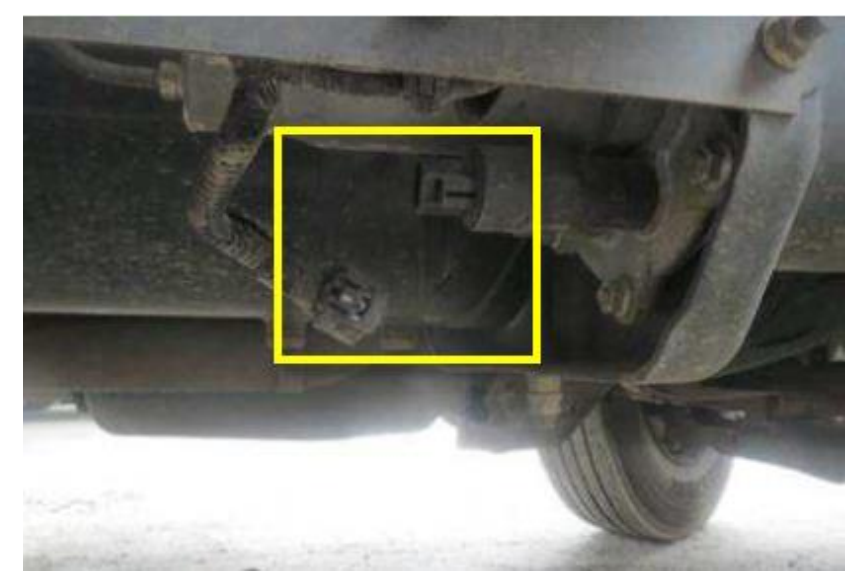

Gambar 7. Sensor airmaster travel.

Pemeriksaan dilakukan juga pada tangki dan selang angin rem gambar 8. Di sini tidak ditemukan kebocoran, air master juga tidak ditemukan kebocoran angin baik pada saat diinjak ataupun tidak.

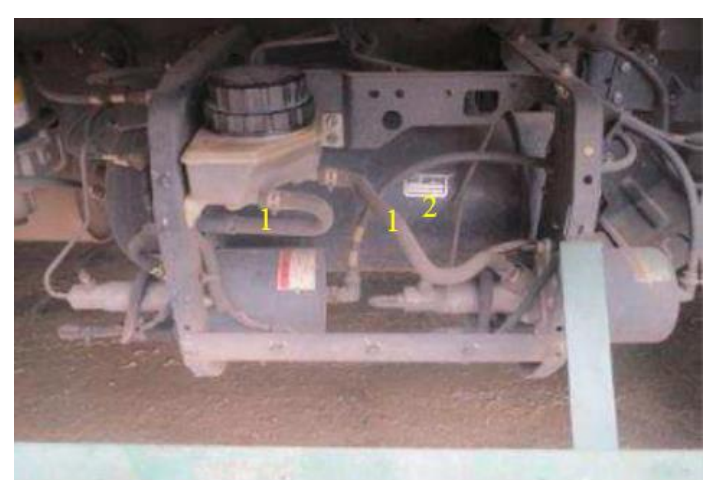

Gambar 8. Tangki angin (2) dan selang rem (1).

Pemeriksaan pada celah kampas rem dengan brake drum, hasilnya sudah lewat dari standar[14], yang dijelaskan pada tabel 1. Sedangkan pada gambar 6 dijelaskan mengenai pengukuran celah kampas rem[15].

Tabel 1. Pengukuran celah kampas rem dengan tromol

\begin{tabular}{lllll}
\hline & Pos 1 & Pos 2 & Pos 3 & Pos 4 \\
\hline Celah atas & 1,2 & 1,2 & 1,2 & 1,2 \\
Celah bawah & 1,2 & 1,2 & 1,2 & 1,2 \\
Standar & $0,30 \mathrm{~mm}$ atau $5-7$ notch & & \\
\hline
\end{tabular}

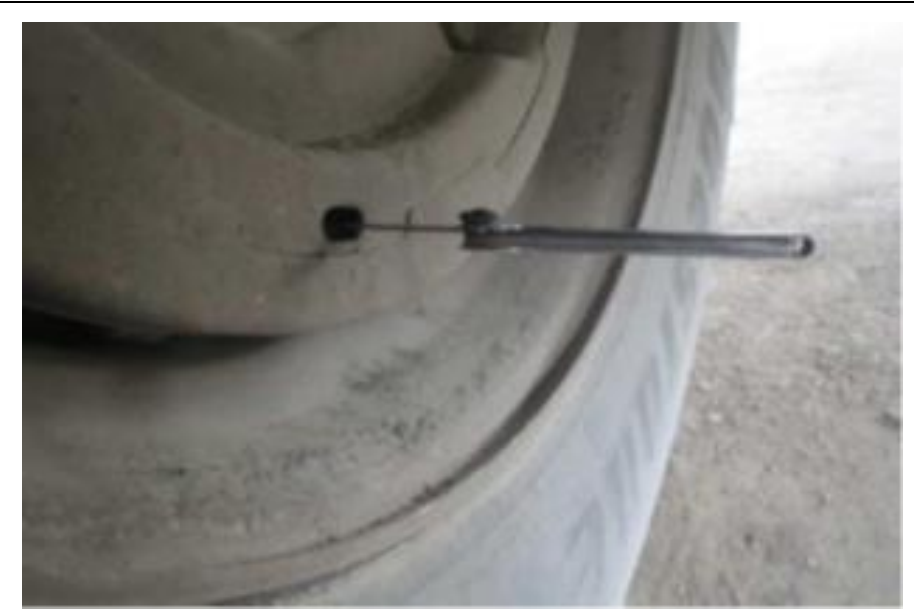

Gambar 9. Pengukuran celah kampas rem. 
ANALISIS KEGAGALAN REM HINO FG 235 DENGAN MENGGUNAKAN METODE FISHBONE ANALISIS

Pada gambar 10 pemeriksaan pipa-pipa minyak rem dari mulai air master ke silinder rem roda, tidak ada yang bocor minyak rem.

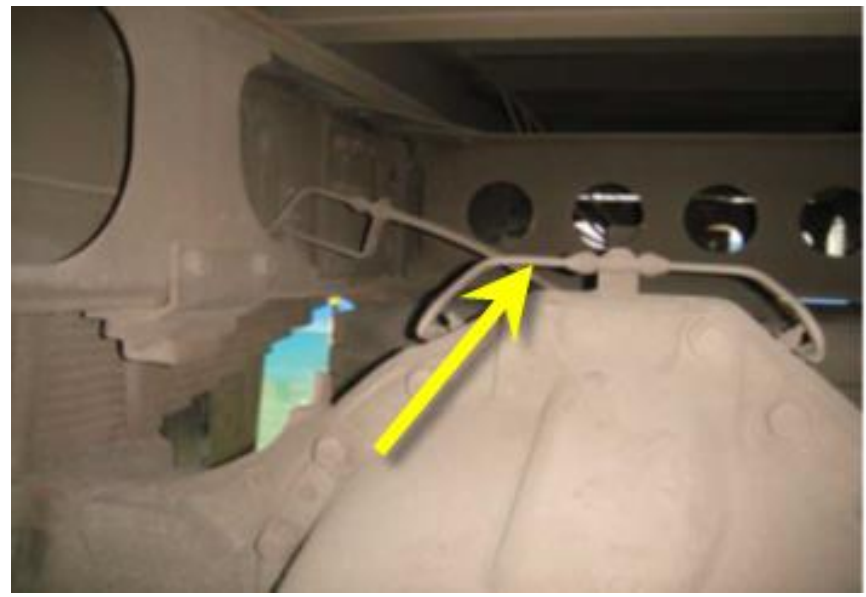

Gambar 10. Pipa minyak rem.

Pada gambar 11 pemeriksaan kebocoran foot brake valve pada saat diinjak dan tidak dan pedal rem, dalam pengecekan yang dilakukan dengan kondisi normal.
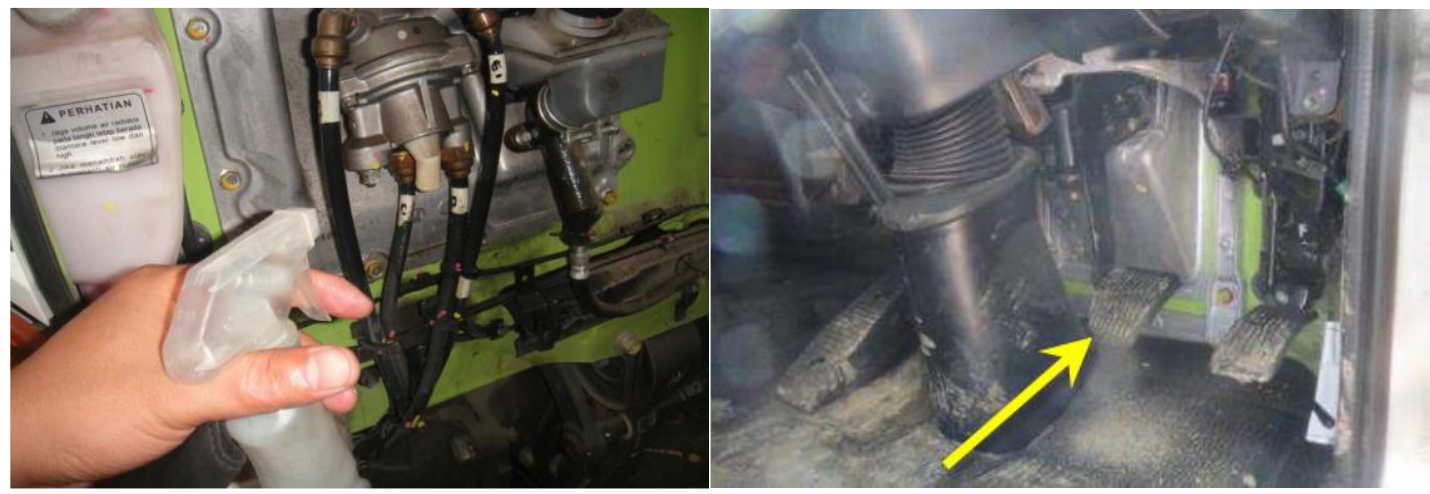

Gambar 11. Pemeriksaan foot brake valve (kiri) dan pemeriksaan pedal rem (Normal).

Pemeriksaan visual pada air master dengan membuka sensornya untuk melihat kebocoran minyak rem atau kebocoran, pada saat diinjak atau tidak (normal), yang dijelaskan pada gambar 12 dan brake piston roda.
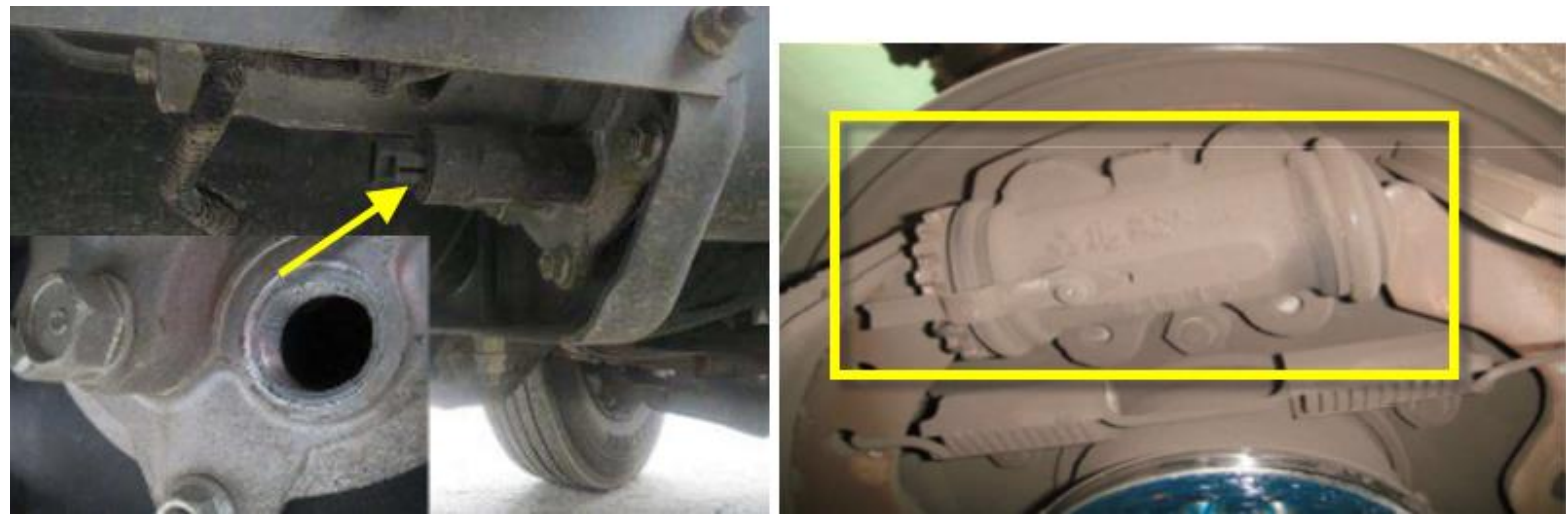

Gambar 12. Pemeriksaan kebocoran dalam air master (Kiri) dan brake piston roda (Kanan).

Pemeriksaan ketebalan kampas rem, hasilnya masih masuk standar semua. 
Tabel 3. Pengukuran ketebalan kampas.

\begin{tabular}{|c|c|c|c|}
\hline Kampas & Pos 1 & $\begin{array}{ll}\text { Pos } 2 & \text { Pos } 3\end{array}$ & Pos 4 \\
\hline Atas & 8 & 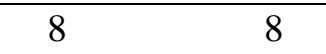 & 8 \\
\hline Bawah & 8 & 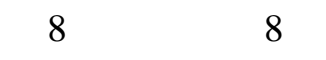 & 8 \\
\hline Standar & Baru: $10 \mathrm{~mm}$ & Minimal: $5 \mathrm{~mm}$ & \\
\hline
\end{tabular}

Gambar 13. Pemeriksaan ketebalan kampas rem[16][8].

Dari semua hasil pemeriksaan yang sudah dilakukan maka kemungkinan terbesar penyebab utama kegagalan rem tersebut adalah dari celah rem yang sudah di luar standarnya sehingga jarak main piston air master terlalu jauh, dimana hal tersebut membutuhkan jumlah angin yang lebih banyak[16], antara konsumsi dan suplai angin tidak seimbang akibatnya angin di tangki tekanannya turun di bawah batas aman sehingga kekuatan rem di roda berkurang akibatnya truk remnya kurang pakem/nyelonong. Posisi gigi netral dan putaran mesin langsam akibatnya suplai angin dari kompresor tidak seimbang dengan kebutuhan rem.

\subsection{Fishbone analysis.}

Dalam analisis menggunakan fishbone analysis ini kegagalan pengereman disebabkan oleh celah kampas rem terlalu besar yang disebabkan keausan.

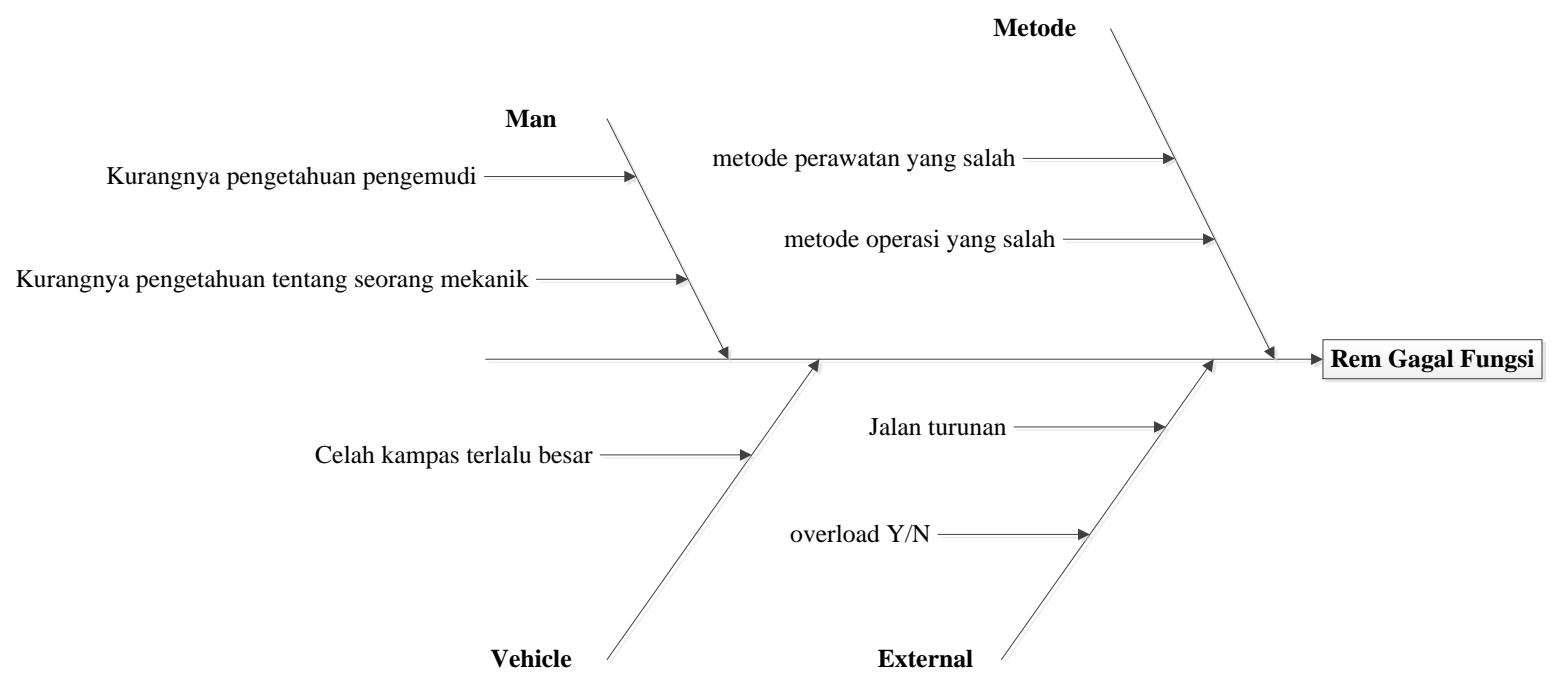

Gambar 14. Diagram fishbone analysis. 


\subsection{Analisa kegagalan rem truk air over hydraulic.}

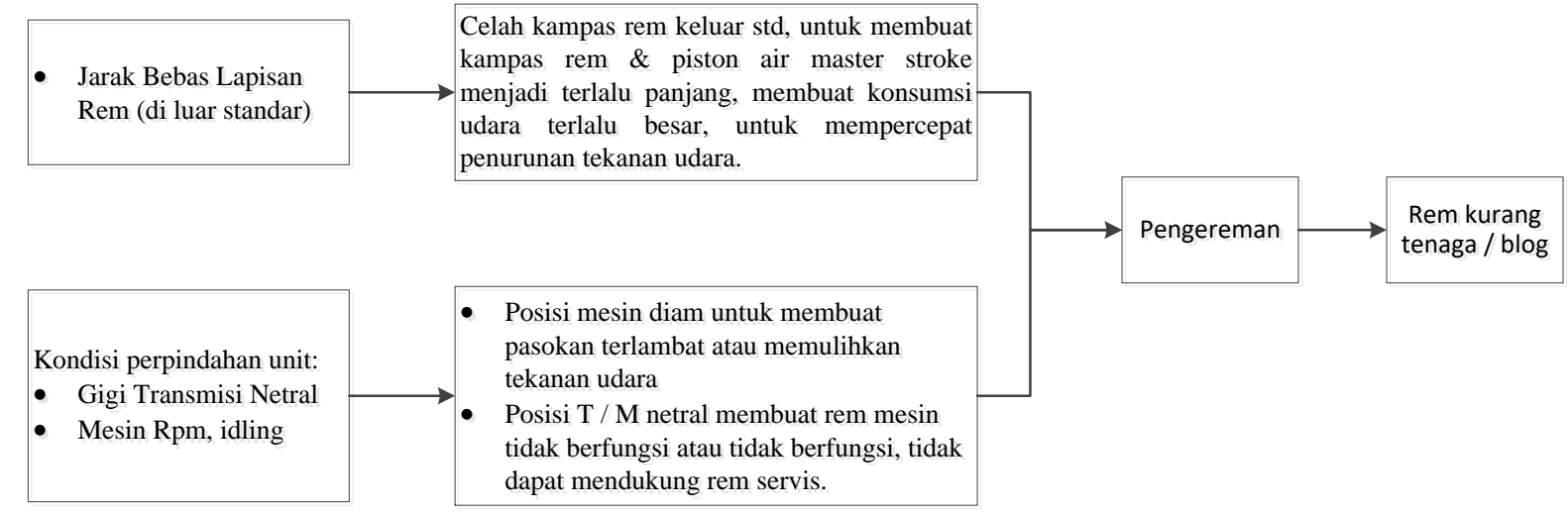

Gambar 15. Diagram analisis rem kurang tenaga/blong.

Semua komponen dipasang kembali sesuai dengan spesifikasinya, penyetelan kembali celah kampas rem sesuai standar dan dilakukan test rem. Dari hasil pengukuran tekanan angin setelah perbaikan dan dilakukan pengetesan rem berfungsi dengan baik.

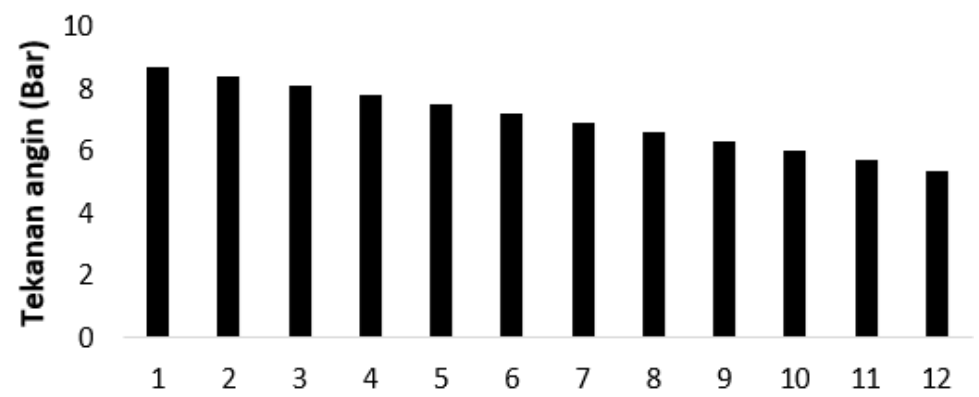

Gambar 16. Hasil pengetesan tekanan angin setelah di setel celah kampas remnya.

\section{SIMPULAN}

Penyebab rem kurang pakem pada truk sampel yang dilakukan penelitian ditemukan dari celah kampas rem yang sudah di luar standar, akibatnya konsumsi angin menjadi besar. Antara pengisian angin dan penggunaan tidak seimbang, akibatnya tekanan angin terus turun dan rem menjadi tidak pakem. Dampak tidak berfungsi dengan baik dalam proses pengereman truk Hino FG 235 tersebut, bisa mengakibatkan kecelakaan dan menimbulkan korban. Perawatan sistem rem harus dilakukan sesuai prosedur yang ada. Untuk penyetelan celah kampas rem pada truk tipe ini FG 235 adalah 0,30 mm atau 5 sampai 7 klik. Jadwal pengecekan rem maksimal setiap service rutin. Penambahan celah kampas rem terjadi karena keausan kampas rem atau brake drum. Pada kasus ini karena berkurangnya ketebalan kampas rem, untuk kasus lain bisa disebabkan karena keausan dari tromolnya. Apabila yang aus tromolnya sudah melebihi diameter standarnya maka tromol juga harus diganti. Langkah preventif dan korektif terkait masalah rem ini sangat sering kita lakukan karena standar dari Hino celah rem dan penyetelan diperiksa setiap $5000 \mathrm{~km}$. Perlu dilakukan training terhadap pengemudi secara berkala untuk meminimalkan kegagalan fungsi pengereman dan menghilangkan kecelakaan, bagaimana cara pengoperasian kendaraan truk Hino FG 235 dengan baik dan benar.

\section{REFERENSI}

[1] P. Marienka, M. Frančák, J. Jagelčák, and F. Synák, "Comparison of Braking Characteristics of Solo Vehicle and Selected Types of Vehicle Combinations," Transp. Res. Procedia, vol. 44, no. 2019, pp. 40-46, 2020, doi: 10.1016/j.trpro.2020.02.007.

[2] X.-D. Wang, Y. Hu, C.-G. Li, and X. Wang, "Modelling and analysis of an air-over-hydraulic 
brake system,” 2004, pp. 805-811, doi: DOI: 10.1243/0954407041581066.

[3] M. S. Tsuyoshi Yamada, "Development and Implementation of Simulation Tool for Vehicle Brake System," SAE Tech. Pap. 2001-01-0034, 2001, p. 8, 2001, doi: https://doi.org/10.4271/2001-01-0034.

[4] A. S. Andrea Fortina, Mauro Velardocchia, "Braking System Components Modelling," SAE Tech. Pap. 2003-01-3335, 2003, doi: https://doi.org/10.4271/2003-01-3335.

[5] R. B. PRADHAN and S. SIVASARAVANAN, "Design and Analysis of Brake Lining of Commercial Car," Int. Res. J. Eng. Technol., vol. 5, no. 8, pp. 1503-1513, 2018.

[6] J. Kamla, T. Parry, and A. Dawson, "Analysing truck harsh braking incidents to study roundabout accident risk," Accid. Anal. Prev., vol. 122, no. May, pp. 365-377, 2019, doi: 10.1016/j.aap.2018.04.031.

[7] L. K. V.S. Shaisundaram, S. Karthick, "Implementation of vacuum braking system in four wheeler," 2020, doi: https://doi.org/10.1016/j.matpr.2020.06.190.

[8] P. Grygorcewicz and A. Tywoniuk, "Tests and Selection Methodology for Brake Linings Friction Material," J. KONES. Powertrain Transp., vol. 21, no. 1, pp. 91-97, 2014, doi: 10.5604/12314005.1134057.

[9] Q. Parts, "Quality Parts, the Perfect Fit ${ }^{\mathrm{TM}}$ Quick Reference Reference Parts Parts Catalog Catalog Model Year Year Edition," 2004.

[10] V. G. I. D V Tretsiak, S V Kliauzovich, K Augsburg, J Sendler, "Research in hydraulic brake components and operational factors influencing the hysteresis losses," https://journals.sagepub.com/doi/10.1243/09544070JAUTO673, vol. 222, no. 9, pp. 16331645, 2008, doi: https://doi.org/10.1243/09544070JAUTO673.

[11] C. L. and X. W. XingDong Wang, YuJing Hu, "Dynamic Characteristics Analysis of Brake System for Heavy-Duty Off-Highway Vehicle," J. Commer. Veh., vol. 113, no. 2, pp. 278-288, 2004, [Online]. Available: https://www.jstor.org/stable/44718822.

[12] M. R. A. Putra and D. D. D. P. Tjahjana, "Fractures on braking component and relations to land-based transportation accident," Procedia Struct. Integr., vol. 27, no. 2019, pp. 147-154, 2020, doi: 10.1016/j.prostr.2020.07.020.

[13] G. Xu, D. Song, D. Zhang, X. Zhang, and S. Sha, "A novel mechanical design of disc brakes for fault diagnosis and monitoring positive braking pressure in mine hoist," vol. 11, no. 4, pp. 1-16, 2019, doi: 10.1177/1687814019842494.

[14] B. O. E. Sfqmbdf et al., "Drum Brake System Inspection and Service."

[15] Z. Wang et al., "Talking about the Automobile Braking System," 2017, doi: 10.1088/1757899X/274/1/012141.

[16] M. H. Hussin, A. R. A. Bakar, M. R. Jamaluddin, and R. Szlapka, "Effects of lining thickness on squeal in drum brake assembly: Experimental investigations," Int. J. Veh. Struct. Syst., vol. 2, no. 2, pp. 69-73, 2010, doi: 10.4273/ijvss.2.2.04. 